\title{
Usefulness Analysis of Urine Samples for Early Screening of Human Papilloma Virus Infection
}

SHORT

COMMUNICATION

\author{
Yoon Sung Choi ${ }^{1}$, Hyunwoo Jin ${ }^{2}$, Kyung Eun Lee \\ ${ }^{1}$ Department of Thoracic and Cardiovascular Surgery, Inje University Haeundae Paik Hospital, ${ }^{2}$ Department of Clinical Laboratory Science, College \\ of Health Sciences, Catholic University of Pusan, Busan, Korea
}

\begin{abstract}
Human papilloma virus (HPV) is known to be a major cause of cervical cancer. In Korea, although the mortality of cervical cancer has decreased, HPV infection rates are increasing rapidly in young women. One of the reasons for a high rate of human immunodeficiency virus (HIV) infection appears to be associated with a low frequency to visit gynecology clinics because of the uncomfortable sampling process for HPV testing. Therefore, it is necessary to develop a non-invasive method, such as urine testing to diagnose cervical cancer rather than use of the existing invasive method. This study aimed to test validity of HPV DNA detection in urine specimens that can be easily collected from women. Paired vaginal discharge and urine samples were collected prospectively from 203 women who visited the local hospital between January and August 2018 in Busan, Korea. By using the Virocheck ${ }^{\circledR}$ assay kit (Optipharm), we found that 17.2\% (35/203) of vaginal discharge samples were HPV positive and 82.8\% (168/203) were HPV negative. In urine samples, 15.8\% (32/203) were HPV positive and $84.2 \%(171 / 203)$ were HPV negative. The co-incident rate for HPV DNA detection was $84.8 \%$ in both vaginal discharge and urine samples. These results suggest that the HPV DNA detection using urine samples might be an alternative way to diagnose HPV infection in a non-invasive way. This analytical approach can be utilized as a screening test to identify HIV-infected patients who need a follow-up process by using urine samples.
\end{abstract}

(J Cancer Prev 2019;24:240-244)

Key Words: Human papilloma virus, Vaginal discharge, Urine

\section{INTRODUCTION}

Cervical cancer is the third most commonly diagnosed cancer and the ninth leading cause of cancer death among women in Korea [1]. The main cause of cervical cancer is human papilloma virus (HPV) infection. The HPV family is comprised of a group of small (50-55 $\mathrm{nm}$ in diameter and $-8 \mathrm{~kb}$ in length) double-stranded DNA viruses, including more than 200 genotypes that infect the keratinocytes of human skin and mucosa, causing a variety of lesions, such as skin warts, genital warts, papillomas, cervical intraepithelial lesions, and also cancer [2,3]. Most HPV infections are asymptomatic, and the outcome of HPV infection is variable [4]. Approximately $90 \%$ of HPV infections are cleared by the host immune system [5]. However, approximately $10 \%$ to $12 \%$ of human immunodeficiency virus infection which is caused by specific types of high-risk HPV is persistent which can lead to invasive cancer $[6,7]$.

In recent years, the prevalence of HPV in young women has increased in many countries [8]. Other studies have shown that the rates of HPV infections that causes cervical cancer are highest among young women, especially 18 to 29 years [9]. Therefore, screening tests are very important for early diagnosis and management of HPV infection in young women. However, screening test using cervical samples are limited because they are, in general, invasive. According to a gynecological survey of 1,039 women in Korea, only $49.9 \%$ visited gynecology, and $56 \%$ of the women in their 20s did not visit gynecology clinics [10]. One reason for a low frequency to visit gynecology clinic is due to the

Received October 20, 2019, Revised December 17, 2019, Accepted December 17, 2019

Correspondence to: Kyung Eun Lee

E-mail: kelee@cup.ac.kr, ORCID: Kyung Eun Lee, https://orcid.org/0000-0001-9543-4159

Copyright (C) 2019 Korean Society of Cancer Prevention

(c) This is an Open Access article distributed under the terms of the Creative Commons Attribution Non-Commercial License (http://creativecommons.org/licenses/by-nc/4.0) which permits unrestricted non-commercial use, distribution, and reproduction in any medium, provided the original work is properly cited. 
uncomfortable sampling process for HPV testing [11,12].

Considering these problems, it is necessary to use a non-invasive method, such as urine testing, to diagnose HPV infection rather than the conventional invasive method [13]. HPV detection in urine samples has been reported as one of the most effective non-invasive methods for early screening of cervical cancer in young women $[14,15]$. In a recent meta-analytical study, the detection of high-risk HPV in urine samples was found to have high accuracy when compared with the detection in cervical samples, with a sensitivity of $77 \%$ and specificity of $88 \%$ [15]. However, few studies have evaluated the clinical performance of urine-based HPV detection in the prediction of cervical precancerous lesions and cancer in Korea. Therefore, this study aimed to evaluate the validity of urinary HPV DNA testing.

\section{MATERIALS AND METHODS}

\section{Participants and clinical samples}

To evaluate the performance of molecular diagnostic methods for HPV detection, paired vaginal discharge and urine samples were collected prospectively from 203 women who visited the local hospital between January and August 2018 in Busan, Korea. Their ages ranged from 18 to 81 years (median age: 45.81 years). This study was approved by the Institutional Ethics Committee of Catholic University of Pusan (approval number CUP IRB 18-01-003). Study participants provided approximately $15 \mathrm{~mL}$ of urine samples. Each urine sample was washed with normal saline. Briefly, $15 \mathrm{~mL}$ urine sample was centrifuged at $1,500 \times g$ for 10 minutes. After removing the supernatant, the pellet was resuspended in $1 \mathrm{~mL}$ of normal saline and transfer to $1.5 \mathrm{~mL}$ tube. The vaginal discharge samples were collected by a clinician using liquid based cytology bottle. Briefly, vaginal discharge samples were transferred to $1.5 \mathrm{~mL}$ tube and centrifuged at $11,000 \times g$ for 5 minutes. After removing the supernatant, the pellet was resuspended in $1 \mathrm{~mL}$ of normal saline and used for the HPV test.

\section{Genomic DNA extraction from vaginal discharge and urine samples}

Genomic DNA was extracted from vaginal discharge and urine samples using the Accuprep ${ }^{\circledR}$ Genomic DNA Extraction Kit (Bioneer, Daejeon, Korea) according to manufacturer instructions. The vaginal discharge and urine samples were washed by addition of $1 \mathrm{~mL}$ saline, followed by incubation for 3 minutes at room temperature, and centrifugation for 2 minutes at $12,000 \times g$. The supernatant was discarded, and the pellet was washed twice with $1 \mathrm{~mL}$ absolute ethanol for re-hydration. The protein degraded with 200 of PBS buffer and $20 \mu \mathrm{L}$ of proteinase $\mathrm{K}$ and added $200 \mu \mathrm{L}$ of gel binding buffer to the sample. Samples were mixed immediately by vortex mixing, followed by incubation at $60^{\circ} \mathrm{C}$ for 10 minutes. Thereafter, $400 \mu \mathrm{L}$ of absolute ethanol was added to samples and mixed well, and transferred to the lysate in the upper reservoir of the binding column tube, followed by centrifugation at $9,000 \times g$ for 1 minute. The solution from the collection tube was discarded and the column was then washed twice with WA1 and WA2 from the kit. Finally, DNA was eluted with $50 \mu \mathrm{L}$ of elution buffer at room temperature for at least 1 minute and centrifuged at $9,000 \times g$ for 1 minute to elute.

\section{Quantitative PCR TaqMan assay targeting human papilloma virus E6/E7 genomic DNA}

Detection of HPV E6/E7 DNA in vaginal discharge and urine samples was performed by the qPCR TaqMan assay using the HPV ViroCheck ${ }^{\circledR}$ assay kit (Optipharm, Osong, Korea). This was based on HPV E6/E7 oncogene detection using ABI 7,500 Fast (Applied Biosystems, Foster City, CA, USA) real-time PCR systems for thermalcycling and fluorescence detection.

The PCR primers and the corresponding TaqMan probes for detection of HPV genotypes were designed for three different sets of HPVs (set 1: FAM-HPV genotype 16, HEX-HPV genotype 31, 33 , 35. 52, and 58, Cy5-IC; set 2: FAM-HPV genotype 18, HEX-HPV genotype 39, 45, 59, and 68, Cy5-IC; set 3: HEX-HPV genotype 53 . 56, 66, 51, and 69; and glyceraldehyde-3-phosphate dehydrogenase [GAPDH]: FAM).

Real-time PCR amplification for HPV E6/E7 DNA was performed in a total volume of $20 \mu \mathrm{L}$ containing $10 \mu \mathrm{L} 2 \times$ Thunderbird probe qPCR mix (Toyobo, Osaka, Japan), $5 \mu \mathrm{L}$ primer, $3 \mu \mathrm{L}$ template DNA, and distilled water (D.W.) to hive a final volume of $20 \mu \mathrm{L}$ for each sample. The multiplex qPCR assay detected HPV E6/E7 genes simultaneously in a single tube by incorporating three targets specific TaqMan probes, which were labeled with different fluorophores (FAM, HEX, and Cy5). Positive and negative controls were included throughout the procedure. No-template controls with sterile D.W. instead of template DNA were incorporated into each run. Cycling conditions were $95^{\circ} \mathrm{C}$ for 3 minutes, followed by 40 cycle of $95^{\circ} \mathrm{C}$ for 3 seconds and $55^{\circ} \mathrm{C}$ for 30 seconds. The HPV DNA was identified by determining the cycle threshold which is the number of PCR cycle required for the fluorescence to exceed a value significantly higher than the background fluorescence. To avoid false negative due to degradation of DNA, GAPDH was used as a control. 


\section{Statistical analysis}

Statistical analysis was performed using IBM Statistical Package for the Social Sciences (SPSS) for Windows Standard ver. 19.0 (IBM Corp., Armonk, NY, USA). Fisher exact test was performed to assess the relationship between the HPV positive prevalence of vaginal discharge and urine samples. A $P$-value less than 0.05 was considered to be statistically significant.

\section{RESULTS}

1. Detection of human papilloma virus E6/E7 genomic DNA by the quantitative PCR TaqMan assay

Analysis of vaginal discharge samples using the qPCR TaqMan assay showed that $17.2 \%$ (35/203) were HPV positive and $82.8 \%$ (168/203) were HPV negative. In urine samples, 15.8\% (32/203) were HPV positive and 84.2\% (171/203) were HPV negative. In both clinical samples, $12.3 \%$ (25/203) of all cases were concurrently HPV positive and 79.3\% (161/203) of all cases were HPV negative. Among the 17.2\% (35/203) of HPV positive cases in vaginal discharge samples, $4.9 \%$ (10/203) were HPV negative in urine samples. Among the $15.8 \%$ of HPV positive cases (32/203) in urine samples, 3.4\% (7/203) were HPV negative in vaginal discharge samples. The co-incident rate for HPV E6/E7 genomic DNA detection in both vaginal discharge and urine samples was $84.8 \%$. These results indicate that there is a correlation between the vaginal discharge and urine samples for HPV E6/E7 genomic DNA detection $(P<0.001$; Table 1$)$.

2. Human papilloma virus genotype distribution based on the human papilloma virus E6/E7 genomic DNA sequence

A total of 203 samples were analyzed using the HPV E6/E7 gene

Table 1. Detection rate of HPV E6/E7 gene DNA by qPCR TaqMan assay

\begin{tabular}{|c|c|c|c|}
\hline \multirow{2}{*}{ Variable } & \multicolumn{2}{|c|}{ Urine } & \multirow{2}{*}{ Total } \\
\hline & HPV positive & HPV negative & \\
\hline \multicolumn{4}{|l|}{ Vaginal discharge } \\
\hline HPV positive & $25(12.3)$ & $10(4.9)$ & $35 / 203(17.2)$ \\
\hline HPV negative & $7(3.4)$ & $161(79.3)$ & $168 / 203(82.8)$ \\
\hline Total & $32 / 203(15.8)$ & $171 / 203(84.2)$ & \\
\hline Co-incident rate (\%) & \multicolumn{2}{|c|}{84.8} & $P<0.001$ \\
\hline
\end{tabular}

Values are presented as number (\%) or percent only. HPV, human papilloma virus. sequence-based assay. Among the $35 \mathrm{HPV}$ E6/E7 gene positive cases in vaginal discharge samples, 9 (25.7\%), 19 (54.2\%), 2 (5.7\%), 10 (28.5\%), and 8 cases (22.8\%) were Group I FAM, Group I HEX, Group II FAM, Group II HEX, and Group III HEX, respectively (Fig. 1).

Among the $32 \mathrm{HPV}$ E6/E7 gene positive cases in urine samples, 7 (21.8\%), 12 (37.5\%), 2 (6.2\%), 8 (25.0\%), and 10 cases (31.2\%) were Group I FAM, Group I HEX, Group II FAM, Group II HEX, and Group III HEX, respectively (Fig. 1).

\section{Comparison of the positivity of human papilloma virus E6/E7 gene according to the age between vaginal discharge and urine samples}

The positivity of HPV E6/E7 genomic DNA in vaginal discharge samples was $18.4 \%$ (7/38), 18.6\% (8/43), 17.5\% (7/40), 18.4\% (7/38), and $13.6 \%(6 / 44)$ in under $20,30,40,50$, and over 60 years of age, respectively. The positivity of HPV E6/E7 gene DNA in urine samples was $21.1 \%$ (8/38), $16.3 \%$ (7/43), $22.5 \%$ (9/40), 7.8\% (3/38), and $11.3 \%(5 / 44)$ in under $20,30,40,50$, and over 60 years of age, respectively (Fig. 2). The age-specific HPV infection rates by detection of HPV E6/E7 gene DNA were different in both vaginal discharge and urine samples, but younger women especially under 40s showed higher HPV infection rate (Fig. 2).

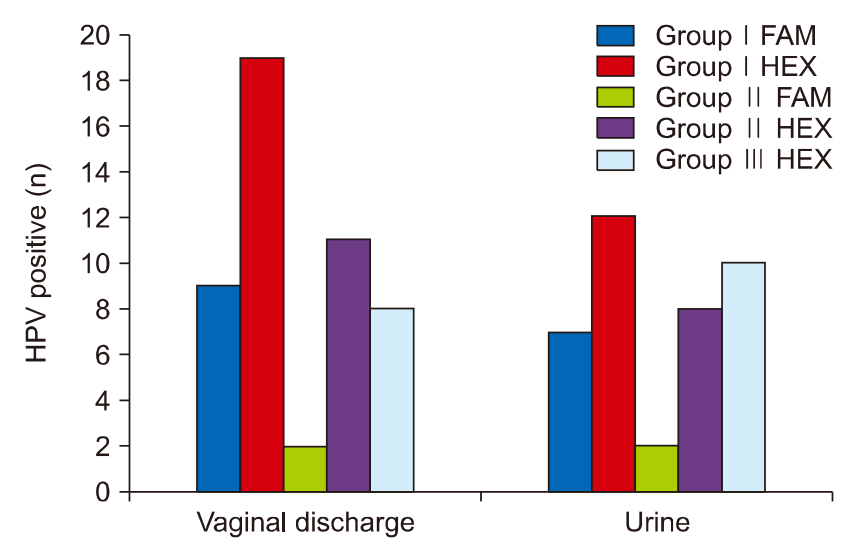

Figure 1. Human papilloma virus (HPV) genotype distribution based on the HPV E6/E7 gene DNA sequence. HPV positive was detected in 35 vaginal discharges and 32 urine samples; 9 (25.7\%), 19 (54.2\%), $2(5.7 \%), 10(28.5 \%)$, and 8 cases $(22.8 \%)$ in vaginal discharge samples, $7(21.8 \%), 12(37.5 \%), 2(6.2 \%), 8(25.0 \%)$, and 10 cases $(31.2 \%)$ in urine samples cases were Group I FAM, Group I HEX, Group II FAM, Group II HEX, and Group III HEX, respectively (Group I FAM: HPV 16; Group I HEX: HPV 31, 33, 35, 52, 58; Group II FAM: HPV 18; Group II HEX: 39, 45, 59, 68; Group III HEX: HPV 51, 53, 56, $66,69)$. 


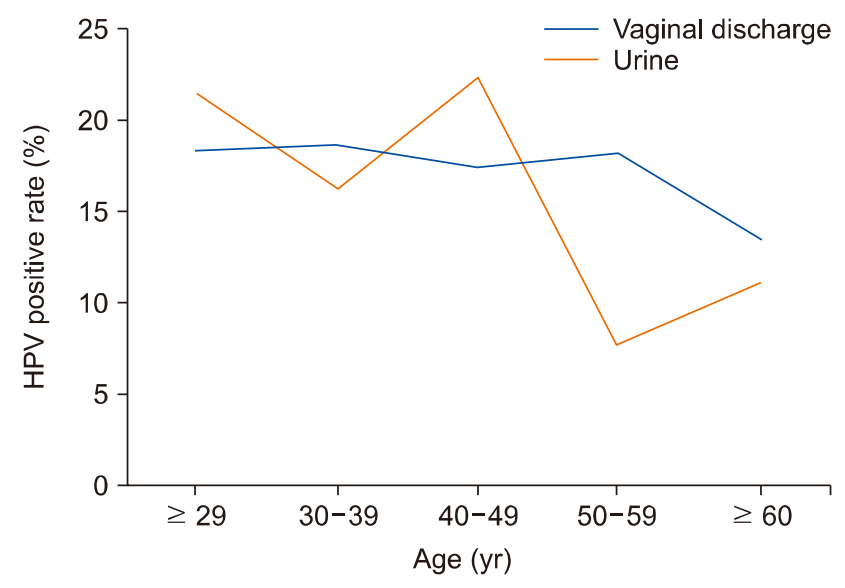

Figure 2. Comparison of positive rate of human papilloma virus (HPV) using ViroCheck ${ }^{\circledR}$ by age between vaginal discharge and urine samples; The average standard deviations of each positive rate between the duplication data for HPV detection.

\section{DISCUSSION}

HPV is one of the most common sexually transmitted infections worldwide. Although the estimated risk of HPV is notably high over a woman's lifetime (over $80 \%$ ), most women who acquire HPV infection do not develop the more serious high-grade cervical neoplasia or invasive cancer because most infections are transient [5,6]. However, HPV persistent infection causes cervical cancer [7]. Other studies have reported a high incidence of HPV infection among young women under 30 years of age [9], raising concerns about the development of cervical cancer as a consequence of persistent HPV infection. In the present study, we analyzed the rate of HPV infection among the general population by age and found the highest positive rates in women in their $40 \mathrm{~s}$, and similar infection rates among young women in their 20s and 30s. Therefore, early detection of HPV is important for preventing cervical cancer. However, young women have a low frequency of visiting gynecology clinics due to the uncomfortable sampling process for HPV testing.

Several studies have reported the usefulness of HPV DNA testing with urine specimens for cervical cancer prevention $[13,16,17]$. However, its validity as compared with that assessed with cervical sample and urine sample from the same person not been well studied. In the present study, the HPV infection rates were compared in vaginal discharge and urine samples from the same population. Using the Virocheck ${ }^{\circledR}$ assay kit (Optipharm), $17.2 \%$ of vaginal discharge samples (35/203) were HPV positive and $15.8 \%$ of urine samples (32/203) were HPV positive. Since the results with urine and vaginal discharge samples were statistically significant, use of urine samples for HPV DNA detection has a practical merit. Using urine samples for HPV DNA testing has a number of advantages. Urine testing is a non-invasive self-sampling method, which would enable frequent samplings as well as the sampling of a large number of populations participating in HPV vaccination programs. Moreover, urine sampling, unlike cervical sampling, is preferable to and better accepted by women, which may lead to better population coverage in screening programs.

While there are some differences in the distribution of HPV genotypes according to countries and regions, HPV 16 accounts for 50\% of all cervical neoplasia, and HPV 18 accounts for about $10 \%$ to $20 \%$ [18]. The prevalence of HPV types 52 and 58 have been reported to be high in Korea [19]. In the present study, Group I HEX was the most frequently positive group, including HPV 31, $33,35,52$, and 58 genotypes, whereas the HPV 16 genotype was the most frequently identified single infection genotype. Therefore, continuous monitoring of high-risk HPV infection is considered to be necessary.

In conclusion, HPV detection was examined as a potential screening tool for the prevention of cervical cancer, and this study found that easy-to-collect urine samples can detect high-risk HPV types. Urine samples are more easily collected which is non-invasive than current screening test collection methods. Therefore, the results from this study can be applied to an non-invasive disgnostic method to identify patients who need follow-up process. In addition, for the early screening of young women who refuse to see a gynecologist, the evaluation of the usefulness of urine samples through cytological diagnosis or sequencing should continue to be expanded.

\section{ACKNOWLEDGMENTS}

This work was supported by RESEARCH FUND offered from Catholic University of Pusan (No. 2016-1-044).

\section{CONFLICTS OF INTEREST}

No potential conflicts of interest were disclosed.

\section{ORCID}

Yoon Sung Choi,

https://orcid.org/0000-0003-1338-4579

Hyunwoo Jin,

https://orcid.org/0000-0003-1773-023X 


\author{
Kyung Eun Lee, \\ https://orcid.org/0000-0001-9543-4159
}

\section{REFERENCES}

1. Oh CM, Won YJ, Jung KW, Kong HJ, Cho H, Lee JK, et al. Cancer statistics in Korea: incidence, mortality, survival, and prevalence in 2013. Cancer Res Treat 2016:48:436-50.

2. Choi YJ, Park JS. Clinical significance of human papillomavirus genotyping. J Gynecol Oncol 2016;27:e21.

3. Nalliah S, Karikalan B, Kademane K. Multifaceted usage of HPV related tests and products in the management of cervical cancer: a review. Asian Pac J Cancer Prev 2015;16:2145-50.

4. Silva J, Ribeiro J, Sousa H, Cerqueira F, Teixeira AL, Baldaque I, et al. Oncogenic HPV types infection in adolescents and university women from North Portugal: from self-sampling to cancer prevention. J Oncol 2011;2011:953469.

5. Cubie HA. Diseases associated with human papillomavirus infection. Virology 2013;445:21-34.

6. Myers ER, McCrory DC, Nanda K, Bastian L, Matchar DB. Mathematical model for the natural history of human papillomavirus infection and cervical carcinogenesis. Am J Epidemiol 2000;151:1158-71.

7. Pinto AP, Crum CP. Natural history of cervical neoplasia: defining progression and its consequence. Clin Obstet Gynecol 2000;43:352-62.

8. Lee JK. HPV DNA test as a diagnostic tool for cervical cancer. Obstet Gynecol Sci 2006;49:261-75.

9. Lee EH, Um TH, Chi HS, Hong YJ, Cha YJ. Prevalence and distribution of human papillomavirus infection in Korean women as determined by restriction fragment mass polymorphism assay. J Korean Med Sci 2012;27:1091-7.

10. Tran N, Stapleton J, Zhang Y, Harlow S, Yang H, Moyer CA.
Contraceptive practices of women visiting a gynecology clinic in Beijing, China. Int J Gynaecol Obstet 2011;112:64-5.

11. Labeit AM, Peinemann F. Determinants of a GP visit and cervical cancer screening examination in Great Britain. PLoS One 2017;12: e0174363.

12. Baek YG. Women's experience with gynecology and accessibility. http://www.womenlink.or.kr/archives/3817?category. Accessed October 11, 2012.

13. Nilyanimit P, Chansaenroj J, Karalak A, Laowahutanont $P$, Junyangdikul P. Poovorawan Y. Comparison of human papillomavirus (HPV) detection in urine and cervical swab samples using the HPV GenoArray Diagnostic assay. Peerj 2017;5:e3910.

14. D'Hauwers KW, Tjalma WA. Screening for human papillomavirus: is urine useful? Indian J Cancer 2009:46:190-3.

15. Cuzick J, Cadman L, Ahmad AS, Ho L, Terry G, Kleeman M, et al. Performance and diagnostic accuracy of a urine-based human papillomavirus assay in a referral population. Cancer Epidemiol Biomarkers Prev 2017;26:1053-9.

16. Arbyn M, Peeters E, Benoy I, Vanden Broeck D, Bogers J, De Sutter P, et al. VALHUDES: a protocol for validation of human papillomavirus assays and collection devices for HPV testing on self-samples and urine samples. J Clin Virol 2018;107:52-6.

17. Asciutto KC, Ernstson A, Forslund O, Borgfeldt C. Self-sampling with HPV mRNA analyses from vagina and urine compared with cervical samples. J Clin Virol 2018;101:69-73.

18. World Health Organization. Human papillomavirus (HPV) and cervical cancer. http://www.who.int/mediacentre/factsheets/fs380/en/. Accessed January 24, 2019.

19. Kim TE, Kim HW, Lee KE. Distribution of human papillomavirus 52 and 58 genotypes, and their expression of p16 and p53 in cervical neoplasia. Korean J Pathol 2014:48:24-9. 